\title{
mRNA of GPRC5B/Raig2, a Novel Orphan Receptor, Expresses in Murine Placentae
}

\author{
Satoshi IMANISHI ${ }^{1}$, Noboru MANABE ${ }^{1)}$, Takako TANAKA ${ }^{1)}$, Reika OKAMOTO ${ }^{1}$, \\ Maki MORITA'), Miki SUGIMOTO') and Hajime MIYAMOTO ${ }^{1)}$ \\ 1) Unit of Anatomy and Cell Biology, Department of Animal Sciences, Kyoto University, Kyoto \\ 606-8502, Japan
}

\begin{abstract}
RNA expression of receptors, retinoic acid inducible gene 2 (GPRC5B/Raig2), estrogen receptor $\alpha(E R \alpha)$, retinoid $X$ receptor $\alpha(R X R \alpha)$, pregnane $X$ receptor (PXR) and germ cell nuclear factor (GCNF), in murine placentae at 14.5, 16.5 and 18.5 day-post coitum (dpc) was examined by reverse transcription-polymerase chain reaction technique. Strong expression of mRNA of GPRC5B/ Raig2, which is a novel member of orphan receptor/G-protein coupled receptor-C and has great effects on cell growth, differentiation and embryogenesis, was first detected in placentae of mice. Moreover, mRNAs of nuclear receptors, ER $\alpha, \mathrm{RXR} \alpha, \mathrm{PXR}$ and GCNF, were also detected in murine placentae. Wide individual differences in these mRNA expression levels were noted. These data indicated that GPRC5B/Raig2 and other nuclear receptors examined in the present study play important roles in placental function of mice. The findings will contribute to the assessment of the toxic effects of endocrine disruptors on placental function.
\end{abstract}

Key words: GPRC5B/Raig2, Mouse, Orphan receptor, Placenta

(J. Reprod. Dev. 48: 627-632, 2002)

A novel group of G-protein coupled receptor-C5 (GPRC5) consists of 4 subtypes, GPRC5A, GPRC5B, GPRC5C and GPRC5D [1-4]. Their endogenous ligands have not been identified, socalled orphan receptors. Since GPRC5A, GPRC5B and GPRC5C are induced by retinoic acid treatment, they are also called retinoic acid inducible gene-1 (Raig1), -2 (Raig2) and -3 (Raig3), respectively. Retinoids, including retinoic acid, have great effects on embryogenesis, cell proliferation, growth, and differentiation, as well as causing death [5, 6], therefore GPRC5A/Raig1, GPRC5B/Raig2 and GPRC5C/Raig3 are considered to play important roles in embryogenesis and/or placental functions [1-4]. However, no detailed knowledge of their roles on

Accepted for publication: May 28, 2002

Correspondence: N. Manabe placental functions has been reported.

Placenta is a specific and essential organ for mammalian development and/or plays a critical role in embryogenesis and embryo growth. Many specific receptors including orphan receptors are known to play important roles in embryogenesis and embryo growth [6-10], but detailed studies of the expression of receptors in placentae have not been reported until now. In the present study, we confirmed the expression of GPRC5B/Raig2 mRNA in murine placentae by reverse transcription-polymerase chain reaction (RT-PCR) technique. Moreover, we assessed mRNA expression of some nuclear receptors, estrogen receptor $\alpha(E R \alpha)$, retinoid $X$ receptor $\alpha(R X R \alpha)$, pregnane $X$ receptor (PXR) and germ cell nuclear factor (GCNF), in murine placentae. 


\section{Materials and Methods}

\section{Preparation of placental tissue}

Female and male ICR mouse purchased from Clea Japan (Tokyo, Japan) were housed under controlled temperature $(24 \pm 2 \mathrm{C})$, lighting (14 h light: $10 \mathrm{~h}$ darkness cycles) and humidity $(80 \pm 5 \%)$ and given a standard diet (CM; Oriental Yeast, Tokyo, Japan) and tap water ad libitum. They received humane care as outlined in the "Guide for the Care and Use of Laboratory Animals" (Kyoto University Animal Care Committee according to NIH No. 86-23; revised 1999). After mating, females detected as having a vaginal plug detection were considered to be at 0.5 day-post coitum (dpc) of pregnancy. Female pregnant mice at the stages of $14.5,16.5$ and $18.5 \mathrm{dpc}(\mathrm{n}=12$ / each group) were sacrificed under anesthesia by diethyl ether in the afternoon (12:00 to 14:00). The placentae were removed, dissected and frozen in liquid nitrogen.

\section{RT-PCR analysis}

For RT-PCR analysis, total RNA was extracted using RNeasy mini kit (Qiagen, Valencia, CA, USA), and then extracted total RNA was reverse transcribed with oligo(dT) primer using $\mathrm{T}$ primed first-strand kit (Amersham Pharmacia Biotech, Piscataway, NJ, USA) to synthesize first strand cDNA. The cDNA was quick-chilled on ice denaturing the RNA-cDNA duplex. The PCR reaction was performed using a Platinum PCR super mix kit (Gibco BRL Life Technologies, Rockville, MD, USA.). All above procedures were performed according to each manufacturer's protocol. Primer pairs specific for partial cDNA sequences of GPRC5B/Raig2 were used: forward; 5'-CTTAC AGCTA GCACA TCACC ATGC-3' and reverse; 5'-CACAC AGCCC TAGCT TTCTT TCC3'; ER $\alpha$ : forward; 5'-GACCA GATGG TCAGT GCCTT-3' and reverse; 5'-ACTCG AGAAG GTGGA CCTGA-3'; RXR $\alpha$ : forward; 5'-GAGCA GCACT GAGGA TATCA AGC-3' and reverse; $5^{\prime}$ GGTCA GGTCT TTGCG TACTG TCC-3'; PXR: forward; 5'-GCTGC ATAAG GAGGA GTATG TGC- $3^{\prime}$ and reverse; 5'-AGGAA CCTGT GAGCA GGATA TGG-3'; GCNF: forward; 5'-CTCAC CCTCT GATGA AGAAC TCC-3' and reverse; $5^{\prime}$ GTTCA GTTGT TCCAG CTGTG AGG-3'. Glyceraldehyde dehydrogenase (GAPDH) was amplified as an intrinsic control using the following primers: forward; 5'-GGGTG GAGCC AAACG
GGTC-3' and reverse; 5'-GGAGT TGCTG TTGAA GTCGC A-3'. The thermal cycling steps carried out in a GeneAmp 2400 (Perkin Elmer Applied Biosystems, Norwalk, CT, USA) were as follows: DNA was denatured at $95 \mathrm{C}$ for $5 \mathrm{~min}$, then PCR was performed for 35 cycles at $95 \mathrm{C}$ for $1 \mathrm{~min}, 59 \mathrm{C}$ for $1 \mathrm{~min}, 72 \mathrm{C}$ for $1 \mathrm{~min}$, and finally for 1 cycle at $72 \mathrm{C}$ for $7 \mathrm{~min}$. The PCR products were electrophoresed in $2 \%$ agarose gel and stained with $1 \mu \mathrm{g} / \mathrm{ml}$ ethidium bromide solution. Ready-load $100 \mathrm{bp}$ DNA ladder (Gibco) was used as a molecular weight marker for electrophoresis. After electrophoresis, the gels were recorded with a digital recorder (LAS-1000, Fiji Film, Tokyo, Japan), and then mRNA expression levels were semiquantified using ImageGauge program (Fuji Film) on a Macintosh computer. The relative abundance of specific mRNA was normalized to the relative abundance of GAPDH mRNA. To confirm the expression of GPRC5B/Raig2 mRNA, the DNA sequence of the PCR product was determined using an automatic DNA sequencer (ABI prism 340; Perkin Elmer Applied Biosystems) according to the manufacturer's protocol.

\section{Statistical analysis}

ANOVA for biochemical data was carried out using StatView-IV on a Macintosh computer. Differences of $\mathrm{P}<0.05$ were considered significant.

\section{Results}

$m R N A$ expression of receptors in murine placentae

Agarose gel electrophoresis of RT-PCR products for the GPRC5B/Raig2, ER $\alpha, R X R \alpha, P X R$, GCNF and GAPDH mRNAs in murine placentae at 14.5, 16.5 and $18.5 \mathrm{dpc}$ were shown in Fig. 1. The placentae with male embryos are shown in the first and second lanes from the left, and those with females are seen in the third and fourth lanes. The placentae located at the terminal area of the uterus horn are shown in the first and third lanes, and those at the vaginal area are shown in the second and fourth lanes. Then, semiquantitative RT-PCR analysis for each mRNA in placentae was summarized in Fig. 2.

Strong expression of GPRC5B/Raig2 mRNA was shown at 14.5 and $16.5 \mathrm{dpc}$, but significantly decreased expression was seen at $18.5 \mathrm{dpc}(\mathrm{P}<0.01$; Figs. 1 and 2). At $18.5 \mathrm{dpc}$, the placenta with male 


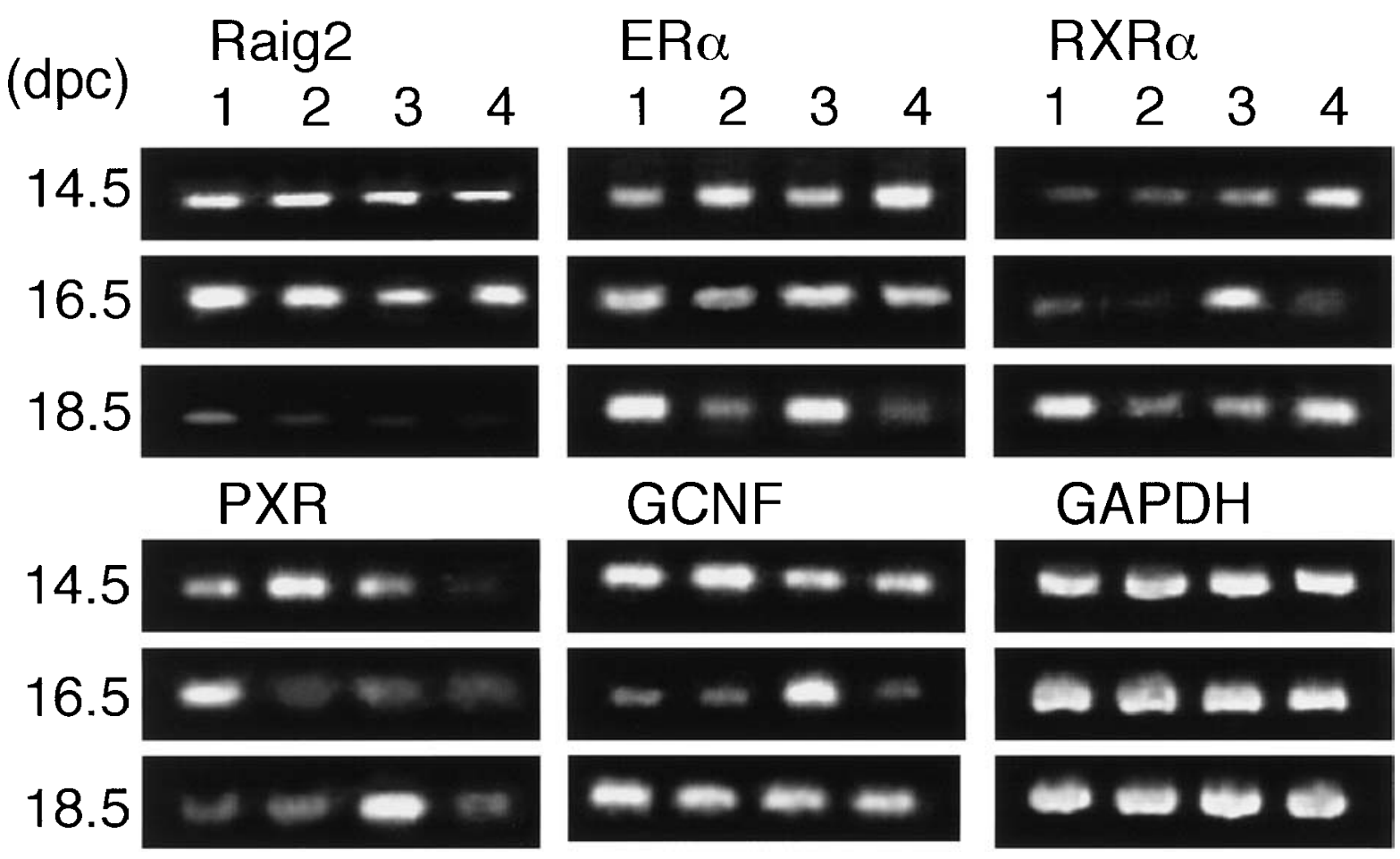

Fig. 1. Representative agarose gel electrophoresis with ethidium bromide staining of PCR products for the GPRC5B/Raig2, $\mathrm{ER} \alpha, \mathrm{RXR} \alpha, \mathrm{PXR}, \mathrm{GCNF}$ and GAPDH mRNAs in murine placentae at 14.5, 16.5 and $18.5 \mathrm{dpc}$. The placentae with male embryos are shown in the first and second lanes, and those with females are seen in the third and fourth lanes. The placentae located at the terminal area of the uterus horn are shown in the first and third lanes, and those at the vaginal area are shown in the second and fourth lanes.

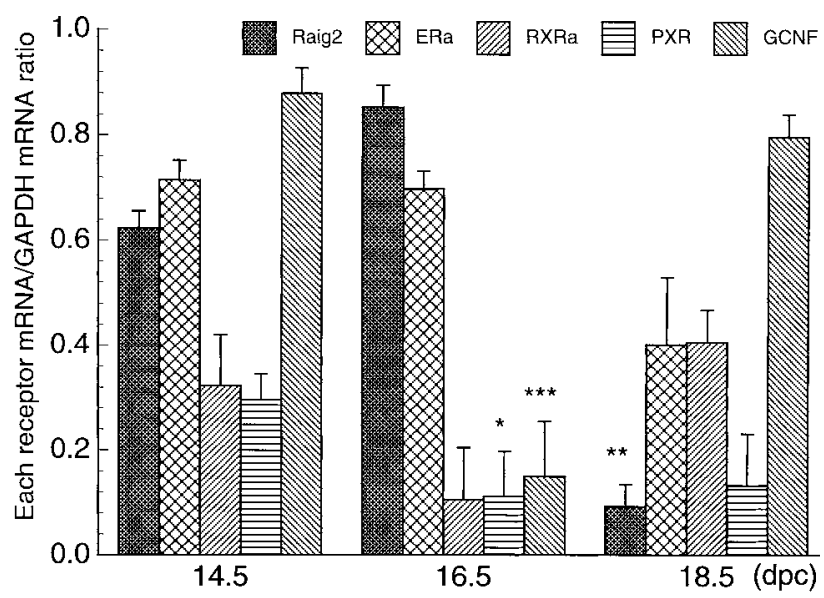

Fig. 2. Semiquantitative analysis of mRNA expression levels of GPRC5B/Raig2, ER $\alpha$, RXR $\alpha$, PXR and GCNF (as a mRNA/GAPDH mRNA ratio) in murine placentae at $14.5,16.5$ and $18.5 \mathrm{dpc}$. All data are shown as means \pm SEM. * ** and ${ }^{* * *}: \mathrm{P}<0.05,0.01$ and 0.001 vs each 14.5 dpc. embryo, which was located at the terminal area of the uterus horn, showed moderate expression, indicating that individual differences in the expression of GPRC5B/Raig2 mRNA exist. The sequence of the PCR product for the corresponding domain of GPRC5B/Raig2 mRNA was determined using an automatic DNA sequencer, indicating that the PCR product corresponded to GPRC5B/Raig2.

ER $\alpha, R X R \alpha, P X R$ and GCNF mRNAs were expressed in murine placentae at 14.5, 16.5 and 18.5 dpc (Figs. 1 and 2). Individual differences in expression of ER $\alpha$ mRNA was seen at 16.5 and 18.5 $\mathrm{dpc}$, that in expression of RXR $\alpha$ and PXR mRNAs were observed at $14.5,16.5$ and $18.5 \mathrm{dpc}$. Individual differences in GCNF mRNA expression was seen at $16.5 \mathrm{dpc}$.

\section{Discussion}

Trace level or no expression of GPRC5B/Raig2 mRNA was detected in human placental tissue, but 
no work on murine placentae has been reported [14]. In the present study, we demonstrated strong expression of GPRC5B/Raig2 mRNA in murine placentae. The receptor family of GPRC includes at least 5 groups [1-4, 11-13]: Group 1: metabotropic glutamate receptors (mGluR); group 2: calcium sensing receptor $(\mathrm{CaR})$ like receptors; group 3: $\gamma$ aminobutyric acid type $B$ receptors $\left(G_{A B A} R s\right)$ like receptors; group 4: pheromone receptors; and group 5: GPRC5 receptors (GPRC5A/Raig1, GPRC5B/Raig2, GPRC5C/Raig3 and GPRC5D). The members of this family, except for the GPRC5 group, have a long N-terminal domain, which in mGluR, $\mathrm{CaR}$ and $\mathrm{GABA}_{\mathrm{B}} \mathrm{R} 1$ is a binding site for endogenous ligands [11-13]. However, GPRC5 receptors have a short $\mathrm{N}$-terminal domain [1-4], and no endogenous ligands have been reported. The members of GPRC family with well-known endogenous ligands are involved in many important physiological and pathological functions in various organs [14-16], so GPRC5 receptors are of great interest and may have important roles in physiological functions. The present data on GPRC5B/Raig2 indicated that this receptor may have critical roles in placental function in mice.

We also confirmed the mRNA expression of ER $\alpha$, RXR $\alpha, P X R$ and GCNF in murine placentae at 14.5, 16.5 and $18.5 \mathrm{dpc}$. These nuclear receptors act as ligand-dependant transcriptional factors [6-12]. Generally, the ligands for nuclear receptors are lipid-soluble substances including steroidhormones, retinoids, vitamin $\mathrm{D}$, thyroid hormones and xenobiotic compounds, but many receptors remain as orphan receptors. High mRNA expression of $E R \alpha$, which plays an important role in estrogenic function, was detected in fetal gonads, brain, bone and many adult organs $[7,10]$. ER $\alpha$ raises female reproductive behavior, initiates sexual differentiation of the fetal brain, and is the main target of endocrine disruptors. Our present results on the expression of ER $\alpha$ mRNA well agree with previous studies $[7,10]$. RXR $\alpha$, a 9-cis-retinoic acid specific receptor, forms heterodimers with other nuclear receptors including retinoic acid receptor, vitamin D receptor, thyroid hormone receptor and some xenobiotic compound receptors [17]. RXR $\alpha$ mRNA is expressed in adult liver, kidney, muscle, intestines, heart, in fetal epithelium, and in the labyrinthine layer of murine placentae. PXR is induced by progesterone, glucocorticoid, pregnenolone and xenobiotic compounds in the mouse, rat and human, but its endogenous ligand has not been identified yet [2026]. PXR forms heterodimer and binds to a specific sequence of DNA containing cytochrome P450-3A (CYP3A) genes. Since the enzymes categorized in the CYP3A subfamily are responsible for the metabolism of endogenous steroid-substrates and steroid-like xenobiotic compounds, a novel signaling pathway for steroid compounds involving PXR may exist. The expression of PXR mRNA has been observed in the ovary, which is a major steroid-producing and metabolizing organ, the uterus, which is a major target of steroid hormones, the liver and intestine but not the placenta [21]. The present data confirmed that PXR mRNAs was expressed in murine placentae, but individual differences were significant. GCNF, which is known as a nuclear receptor $6 \mathrm{~A} 1$ or as a retinoic acid receptor-related testis-associated receptor, lacks known ligands and is therefore referred to as an orphan receptor [19, 27, 28]. GCNF is highly expressed in the nervous system of the developing embryonic and the labyrinthine layer of the placentae in mice. Gene targeting in the mouse shows that GCNF has an essential function during embryogenesis [27]. Our present findings also confirmed the expression of GCNF mRNA in murine placentae. Further studies are in progress in our laboratory to reveal what factors cause individual differences in the expression of receptor mRNAs, for instance, differences in embryo sex, the developmental stage of the embryo, and the implantation part in the uterus and so on.

In conclusion, this paper is the first report confirming the expression of GPRC5B/Raig2 mRNA in placentae of mice. Moreover, mRNA expression of some nuclear receptors, $E R \alpha, R X R \alpha$, PXR and GCNF, in murine placentae was confirmed. This data will contribute to the assessment of the effects of endocrine disruptors on placental function, and further works are in progress to evaluate the toxic effects of some endocrine disruptors on the placentae and embryos.

\section{Acknowledgements}

This work was supported by Grant-in-Aid for Creative Scientific Research (13GS0008) and for Scientific Research (A) (13027241) to N. M. from the 
Ministry of Education, Culture, Sports, Science and Technology, Japan.

\section{References}

1. Cheng Y, Lotan R. Molecular cloning and characterization of novel retinoic acid-inducible gene that encodes a putative G-protein-coupled receptor. J Biol Chem 1998; 273: 35008-35015.

2. Bräuner-Osborne $\mathbf{H}, \quad$ Krogsgaard-Larsen $\mathbf{P}$. Sequence and expression pattern of a novel human orphan G-protein-coupled receptor, GPRC5B, a family $C$ receptor with a short amino-terminal domain. Genomics 2000; 65: 121-128.

3. Robbins MJ, Michalovich D, Hill J, Calver AR, Medhurst AD, Gloger I, Sims M, Middlemiss DN, Pangalos MN. Molecular cloning and characterization of two novel retinoic acid-inducible orphan G-protein-coupled receptors (GPRC5B and GPRC5C). Genomics 2000; 67: 8-18.

4. Bräuner-Osborne $\mathbf{H}$, Jensen AA, Sheppard PO, Brodin B, Krogsgaard-Larsen P, O'Hara P. Cloning and charactarization of a human orphan family C Gprotein coupled receptor GPRC5D. Biochim Biophys Acta 2001; 1518: 237-248.

5. Sharon AR, Peter JM, Ursula CD, de Luca LM. Retinoids in embryonal development. Physiol Rev 2000; 80: 1021-1054.

6. Chambon P. A decade of molecular biology of retinoic acid receptors. FASEB J 1996; 10: 940-954.

7. Evans RM. The steroid and thyroid hormone receptor superfamily. Science 1988; 240: 889-895.

8. Mangelsdorf DJ, Thummel C, Beato M, Herrlich $P$, Schutz G, Umesono K, Blumberg B, Kastner P, Mark M, Chambon P, Evans RM. The nuclear receptor superfamily: the second decade. Cell 1995; 83: 835-839.

9. Perlmann T, Evans RM. Nuclear receptors in sicily: all in the famiglia. Cell 1997; 90:391-397.

10. Tenbaum S, Baniahmad A. Nuclear receptors: Structure, function and involvement in disease. Int J Biochem Cell Biol 1997; 29: 1325-1341.

11. O'Hara PJ, Sheppard PO, Thogersen H, Venezia D, Haldeman BA, McGrane V, Houamed KM, Thomsen C, Gilbert TL, Mulvihill ER. The ligandbinding domain in metabotropic glutamate receptors is related to bacterial perplasmic binding proteins. Neuron 1993; 11: 41-52.

12. Bräuner-Osborne $\mathbf{H}$, Jensen AA, Sheppard PO, O'Hara P, Krogsgaard-Larsen $\mathbf{P}$. The agonist binding domain of the calcium-sensing receptor is located at the amino-terminal domain. J Biol Chem 1999; 274: 18382-18386.

13. Galvez T, Parmentier M-L, Joly C, Malischek B, Kaupmann K, Kuhn R, Bittiger H, Froestl W, Bettler B, Pin JP. Mutagenesis and modeling of the
$\mathrm{GABA}(\mathrm{B})$ receptor extracellular domain support a Venus flytrap mechanism for ligand binding. J Biol Chem 1999; 274: 13362-13369.

14. Pellicciari R, Costantino G. Metabotropic Gprotein-coupled glutamate receptors as therapeutic targets. Curr Opin Chem Biol 1999; 3: 433-440.

15. Brown EM. Physiology and pathophysiology of the extracellular calcium sensing receptor. Am J Med 1999; 106: 238-253.

16. Bettler B, Kaupmann K, Bowery N. GABA receptors: Drugs meet clones. Curr Opin Neurobiol 1998; 8: 345-350.

17. Sapin V, Ward SJ, Bronner S, Chambon P, Dolle P. Differential expression of transcripts encoding retinoid binding proteins and retionic acid receptors during placentation of the mouse. Dev Dyn 1997; 208: 199-210.

18. Masuyama $\mathbf{H}$, HiramatsuY, Mizutani $\mathbf{Y}$, Inoshita $\mathbf{H}$, Kudo K. The expression of pregnane $X$ receptor and its target gene, cytochrome P450 3A1, in perinatal mouse. Mol Cell Endo 2001; 172: 47-56.

19. Morasso MI, Grinberg A, Robinson G, Sargent TD, Mahon KA. Placental failure in mice lacking the homeobox gene Dlx3. Proc Natl Acad Sci USA 1999; 96: 162-167.

20. Pascussi JM, Jounaidi Y, Drocourt L, Domergue J, Balabaud C, Maurel P, Vilarem MJ. Evidence for the presence of a functional pregnane $X$ receptor response element in the CYP3A7 promoter gene. Biochem Biophys Res Commun 1999; 260: 377-381.

21. Kliewer SA, Moore JT, Wade L, Staudinger JL, Watson MA, Jones SA, Mckee DD, Oliver BB, Willson TM, Zetterstrom RH, Perlmann T, Lehmann JM. An orphan nuclear receptor activated by pregnanes defines a novel steroid signaling pathway. Cell 1998; 92: 73-82.

22. Bertilsson G, Heidrich J, Svensson $K$, Asman $M$, Jendeberg L, Sydow-Backman $M$, Ohlsson $R$, Postlind $\mathrm{H}$, Blomquist $\mathrm{P}$, Berkenstam A. Identification of a human nuclear receptor defines a new signaling pathway for CYP3A induction. Proc Natl Acad Sci USA 1998; 95: 12208-12213.

23. Blumberg B, Sabbagh W, Juguilon HJ, Bolado J, van Meter CMJ, Ong ES, Evans RM. SXR, a novel steroid and xenobiotic-sensing nuclear receptor. Genes Dev 1998; 12: 3195-3205.

24. Lehmann JM, Mckee DD, Watson MA, Willson TM, Moore JT, Kliewer SA. The human orphan nuclear receptor PXR is activated by compounds that regulate CYP3A4 gene expression and cause drug interaction. J Clin Invest 1998; 102: 1023-1026. 
25. Schuetz EG, Brimer C, Schuetz JD. Environmental xenobiotics and the antihormones cyproterone acetate and spironolactone use the nuclear hormone pregnane $X$ receptor to activate hormone response element. Mol Pharmacol 1998; 54: 1113-1117.

26. Zhang H, LeCulyse E, Liu L, Hu M, Matoney L, Zhu W, Yan B. Rat pregnane X receptor: molecular cloning, tissue distribution, and xenobiotic regulation. Arch Biochem Biophys 1999; 368: 14-22.

27. Chung ACK, Katz D, Pereira FA, Jackson KJ,
DeMayo FJ, Cooney AJ, O'Malley BW. Loss of orphan receptor germ cell nuclear factor function results in ectopic development of the tail bud and a novel posterior truncation. Mol Cell Biol 2001; 21: 663-677.

28. Süsens U, Aguiluz JB, Evans RM, Borgmeyer U. The germ cell nuclear factor mGCNF is expressed in the developing nervous system. Dev Neurosci 1997; 19: 410-420. 